\title{
CARACTERIZAÇ̃̃O FÍSICO-QUIMICA E ENZIMÁTICA DE UVA 'PATRICIA' CULTIVADA NA REGIÃO DE PRIMAVERA DO LESTE - MT
}

\author{
Physical chemistry and enzymatic characterization of grape 'Patricia' cultivated in \\ Primavera do Leste - MT
}

\author{
Merce Teodora Aguil Santana ${ }^{1}$, Heloísa Helena de Siqueira ${ }^{2}$, \\ Richardson Júnior Lacerda ${ }^{3}$, Luiz Carlos de Oliveira Lima ${ }^{4}$
}

\begin{abstract}
RESUMO
Amostras de uva (Vitis labrusca L.) cv Patrícia, produzidos na região de Primavera do Leste no Estado de Mato Grosso, foram analisadas pelos parâmetros químicos segundo a legislação: $\mathrm{pH}$, sólidos solúveis ( $\left.{ }^{\circ} \mathrm{Brix}\right)$, acidez titulável, vitamina $\mathrm{C}$ e atividade enzimática das enzimas polifenoloxidase (PPO); peroxidase (POD); pectinametilesterase (PME); e poligalacturonase (PG). $\mathrm{O}$ valor de sólidos solúveis (SS) das amostras analisadas foi de $17,69^{\circ}$ Brix. O valor de $\mathrm{pH}$ encontrado foi de 3,69. A acidez titulável (AT) apresentou valor de $0,8 \mathrm{~g}$ de ácido tartárico $/ 100 \mathrm{~mL}$ de suco. $\mathrm{O}$ valor de vitamina $\mathrm{C}$ foi de $17,54 \mathrm{mg} / \mathrm{mL}$. A atividade enzimática da polifenoloxidase (PPO) foi de $22,15 \mathrm{U} / \mathrm{g} / \mathrm{min}$. As atividades enzimáticas para as enzimas peroxidase (POD) e poligalacturonase apresentaram valores de: $11,59 \mathrm{U} / \mathrm{g} / \mathrm{min}$ e $3778,61 \mathrm{U} / \mathrm{g} / \mathrm{min}$, respectivamente. Não foram detectados valores para a atividade enzimática da pectinametilesterase (PME), nas amostras analisadas. Os parâmetros químicos analisados se encontram dentro dos padrões estabelecidos pela legislação. Pelos resultados apresentados a cultivar Patrícia apresenta um valor elevado de vitamina $\mathrm{Ce}$, quando em estado de maturação, apresenta valores elevados da atividade enzimática da poligalacturonase (PG).
\end{abstract}

Termos para indexação: Vitis labrusca, ácido tartárico, enzima.

\begin{abstract}
Grape samples (Vitis labrusca L.) 'Patrícia', produced in the area of Primavera do Leste in the State of Mato Grosso, were analyzed by the chemical parameters according to the legislation: $\mathrm{pH}$, soluble solids ( ${ }^{\circ} \mathrm{Brix}$ ), titrable acidity, vitamin $\mathrm{C}$ and enzymatic activity of the polyfenoloxidase (PPO); peroxydase (POD); pectinmetylesterase (PME); and polygalacturonase (PG). The value of soluble solids (SS) of the analyzed samples it was of $17.69^{\circ}$ Brix. The value of found $\mathrm{pH}$ was of 3.69. The titrable acidity (AT) showed value of $0.8 \mathrm{~g}$ of acid tartaric/100 mL juice. The vitamin $\mathrm{C}$ value was $17.54 \mathrm{mg} / \mathrm{mL}$. The enzymatic activity of the polyfenoloxidase (PPO) was $22.15 \mathrm{U} / \mathrm{g} / \mathrm{min}$. The enzymatic activities for the enzymes peroxidase (POD) and polygalacturonase presented values of: $11.59 \mathrm{U} / \mathrm{g} / \mathrm{min}$ and $3778.61 \mathrm{U} / \mathrm{g} / \mathrm{min}$, respectively. Values were not detected for the enzymatic activity of the pectinmetylesterase (PME) in the analyzed samples. The values of chemical analysis found in this research were in agreement with legislation. For the results presented to 'Patrícia' cultivar a high value of vitamin $\mathrm{C}$ was found and when in maturation stage it presents elevated values of the enzymatic activity of the polygalacturonase (PG).
\end{abstract}

Index terms: Vitis labrusca, tartaric acid, enzyme.

(Recebido em 19 de agosto de 2005 e aprovado em 7 de agosto de 2006)

\section{INTRODUÇÃo}

A cultura de videira (Vitis labrusca L.) foi introduzida no Estado do Mato Grossos por volta de 1992, estando essa viticultura hoje localizada nas regiões de Campo Verde, Primavera do Leste, Nova Mutum, Rondonópolis e Barra do Garças (GIVANINI, 1999).

A cultivar Patrícia (IAC 871-41) é um híbrido IAC de terceira geração. Apresenta cachos grandes (400 a 700g), com ramificações abundantes; os pedicelos, bem formados, favorecem outra excelente característica dessa cultivar, que é sua resistência à degrana. A maturação, que se mostra inicialmente irregular, completa-se perfeitamente; os cachos apresentam boa conservação frigorífica. Introduzida recentemente no Mato Grosso, seu cultivo vem sendo ampliado nessa região, em virtude de suas características agronômicas.

\footnotetext{
1'Doutouranda em Ciência dos Alimentos - Departamento de Ciência dos Alimentos/DCA - Universidade Federal de Lavras/UFLA - Cx. P. 3037 - $37200-000$ Lavras, MG - mercesantana@yahoo.com.br

${ }^{2}$ Doutoranda em Ciência dos Alimentos - Departamento de Ciência dos Alimentos/DCA - Universidade Federal de Lavras/UFLA - Cx. P. 3037 - $37200-000$ Lavras, MG - heloisa.elias@yahoo.com.br

${ }^{3}$ Mestre em Ciência dos Alimentos - Departamento de Ciência dos Alimentos/DCA - Universidade Federal de Lavras/UFLA - Cx. P. 3037 - $37200-000$ Lavras, MG - lacerda28@yahoo.com.br

${ }^{4}$ Doutor, Professor - Departamento de Ciência dos Alimentos/DCA - Universidade Federal de Lavras/UFLA - Cx. P. 3037 - $37200-000$ - Lavras, MG Icolima@ufla.br
} 
Nas células vivas, ocorrem várias e ininterruptas reações que são catalizadas por enzimas, e elas têm como função acelerar a velocidade das reações químicas celulares. As enzimas são, em sua maioria, proteínas com uma estrutura química espacial, contendo um centro ativo, denominado apoenzima e algumas vezes, um grupo não protéico, denominado coenzima. As enzimas exercem um papel importantíssimo no metabolismo celular.

Os componentes mais importantes da parede celular são os polissacarídeos celulose, hemicelulose e as substâncias pécticas, embora proteínas, lignina, água, cutina e suberina, assim como compostos inorgânicos, possam também estar presentes. (GOODWIN \& MERCER, 1982). As substâncias pécticas atuam como matérias cimentantes localizadas na lamela média, derivam dos ácidos poligalacturônicos e ocorrem nas formas de protopectina, ácido pectínico e ácido péctico (SALUNKHE et al., 1991). Os compostos pécticos mais abundantes são os ácidos poligalacturônicos, formados principalmente por cadeias não ramificadas de resíduos de ácido com ligação a-1,4-D-galacturônico, metil esterificados.

Existem evidências de que o amaciamento do fruto durante o amadurecimento é acompanhado pelo aumento na solubilização de substâncias pécticas na parede celular e lamela média e que um incremento no teor de pectina solúvel em água é observado com o decorrer do amaciamento. Grandes mudanças na estrutura péctica acompanham o amadurecimento de muitos frutos. Essas mudanças na estrutura têm sido atribuídas à ação de poligalacturonases (PG) e pectinasmetilesterases (PME) (SEYMOUR et al., 1993).

A enzima PME é conhecida por desesterificar compostos pécticos constituintes da parede celular das plantas. A hidrólise de grupos metil-éster, catalisada por essa enzima, produz uma pectina com menor grau de metilação, que sofre clivagem pela PG. Assim, o efeito sinergístico dessas duas enzimas tem um importante papel no processo de amolecimento do fruto durante o estádio de amadurecimento. A desmetilação da pectina resulta em um maior número de grupos carboxílicos, o que pode facilitar a ação da poligalacturonase, que degrada substâncias pécticas, preferivelmente desesterificadas (FRY, 1986).

Existem numerosas enzimas oxidativas que promovem alterações nos alimentos. A maioria das reações metabólicas em frutos e hortaliças é catalisada por enzimas (CHITARRA \& CHITARRA, 1990). Entre elas a polifenoloxidase (PPO), é encontrada praticamente em todos os tecidos vegetais, resultando na formação de pigmentos escuros, proporcionando mudanças indesejáveis nas características sensoriais dos produtos. A polifenoloxidase aparentemente se torna envolvida no metabolismo quando há ruptura da célula e vacúolos com mistura dos seus conteúdos. Isso ocorre durante a senescência quando a integridade da célula é rompida, ativando a PPO latente (PIMENTA, 2001).

Objetivou-se, no presente trabalho, determinar a composição química: $\mathrm{pH}$, sólido solúveis (SS), acidez titulável (AT), teores de Vitamina C, atividade enzimática de: polifenoloxidase (PPO), peroxidase (POD), pectinametilesterase $(\mathrm{PME})$ e poligalacturonase $(\mathrm{PG}) \mathrm{de}$ amostras da cultivar Patrícia, cultivada na região de Primavera do Leste no Estado do Mato Grosso, verificando sua qualidade para industrialização e consumo in natura.

\section{MATERIAL E MÉTODOS}

Foram utilizados nesse estudo $15 \mathrm{~kg}$ de uvas da cv Patrícia (Vitis labrusca), da safra de julho de 2004, produzidas em um parreiral de 08 anos, com área de 05 ha, em sistema de condução latada e irrigados com sistema de irrigação por microaspersão, pertencente à Fazenda Juriti localizada no município de Primavera do Leste - MT, distante $230 \mathrm{Km}$ da capital Cuiabá, cuja localização é Latitude: $15^{\circ} 33^{\prime} 45^{\prime}$ S; Longitude: 54 ${ }^{\circ} 17^{\prime} 41,8^{\prime \prime} \mathrm{Wgr}$; a precipitação pluviométrica é em torno de $1.560 \mathrm{~mm} / \mathrm{ano}$, variando de $5 \mathrm{~mm}$ a $300 \mathrm{~mm}$ como média mensal, sendo abundante no verão entre outubro a abril, com o inverno seco de maio a agosto. A umidade relativa do ar tem a média variando de $65 \%$ a $87 \%$ e temperatura média variando de $18^{\circ} \mathrm{C}$ a $24^{\circ} \mathrm{C}$, com temperatura mínima oscilando entre $10^{\circ} \mathrm{C}$ e $19^{\circ} \mathrm{C}$ e a temperatura máxima variando entre $29^{\circ} \mathrm{C}$ e $34^{\circ} \mathrm{C}$. As amostras foram coletadas inteiramente ao acaso, ao amanhecer, no parreiral em forma de ziguezague e imediatamente armazenadas em caixas de papelão recobertas com papel manteiga, com capacidade para $6 \mathrm{~kg}$. As amostras foram encaminhadas, no mesmo dia, para o Laboratório de Fisiologia Pós- Colheita de Frutas e Hortaliças da Universidade Federal de Lavras - MG, em caixas térmicas (isopor), devidamente refrigeradas com gelo. No laboratório as amostras foram submetidas a um tratamento com hipoclorito de sódio a $5 \%$, separadas em lotes de $2,5 \mathrm{~kg}$, congeladas em nitrogênio líquido $\left(-196^{\circ} \mathrm{C}\right)$ e estocadas em Deep Frezing $\left(-80^{\circ} \mathrm{C}\right)$. No momento da execução das análises as amostras foram descongeladas em geladeira $\left(3,5^{\circ} \mathrm{C}\right)$ por 12 horas. Para execução das análises foram retiradas as sementes e trituradas as bagas com casca e polpa. Todas as análises foram executadas em triplicata para maior confiabilidade nos resultados. O experimento foi conduzido em um delineamento inteiramente casualizado (DIC), com 1 
tratamento e seis (6) repetições, sendo o peso de $2,5 \mathrm{~kg}$ considerado uma repetição.

$\mathrm{O} \mathrm{pH}$ foi determinado utilizando-se um peagâmetro Schott Handylab, segundo técnica da AOAC (1992). Os sólidos solúveis (SS) foram determinados por refratometria, em refratômetro digital ATAGO PR-100, com compensação de temperatura automática a $25^{\circ} \mathrm{C}$, e expressos em ${ }^{\circ} \mathrm{Brix}$, segundo a AOAC (1992). A determinação da acidez titulável (AT) foi realizada por titulação com solução de $\mathrm{NaOH} 0,1 \mathrm{~N}$, até pH 8,2, usando como indicador fenolftaleína, de acordo com o AOAC (1992). A vitamina C ou ácido ascórbico foi determinado pelo método colorimétrico, segundo Strohecker \& Henning (1967), com leitura realizada em espectrofotômetro Beckman 640B, com sistema computadorizado e os resultados foram expressos em $\mathrm{mg}$ de ácido ascórbico/100 mL de suco. A determinação da atividade enzimática da enzima polifenoloxidase (PPO) foi determinada pelo método descrito por Ponting \& Joslyng (1948), utilizando-se extrato da amostra sem DOPA como branco. A determinação da enzima pectinametilesterase (PME), foi segundo método descrito por Buescher \& Furmanski (1978) para obtenção do extrato e a determinação da atividade enzimática pelo método descrito por Hultin et al. (1966). A obtenção do extrato de poligalacturonase (PG) seguiu técnica descrita por Buecher \& Furmanski (1978) e a determinação da atividade enzimática pelo método descrito por Markovic et al. (1975). A determinação da atividade enzimática peroxidase (POD), seguiu as técnicas de Hultin et al. (1966) e Ratner et al. (1969), com modificações de Vilas-Boas (1995).

\section{RESULTADOS E DISCUSSÃO}

Os valores de $\mathrm{pH}$, sólidos solúveis (SS), acidez titulável (AT), vitamina $\mathrm{C}$ e atividade enzimática das enzimas polifenoloxidase (PPO), pectinametilesterase (PME), peroxidase (POD) e poligalacturonase (PG) da cultivar Patrícia, cultivada na região de Primavera do Leste no Estado do Mato Grosso verificam-se pela Tabela 1.

O pH em uvas varia de 3,5 a 4,5 e é um dos responsáveis pelas características organolépticas e coloração de vinhos e sucos, juntamente com acidez total e outros compostos relacionados (RIZZON \& GATTO, 1987; SACHS, 2001).

O valor de sólidos solúveis da cv Patrícia (17,69 ºrix) são semelhantes aos observados por Souza-Leão \& Pereira (2001), que obteve teores de sólidos solúveis de 14,05 Bix na variedade Canner e 19, $6^{\circ}$ Brix na Vênus. A concentração de sólidos solúveis (SS), determina a doçura do fruto durante a maturação e está relacionada ao seu sabor (KAWAMATA, 1997; RHODES, 1980).
Tabela 1 - Valores de pH, sólidos solúveis (SS), acidez titulável (AT), vitamina $\mathrm{C}$ e atividade enzimática das enzimas polifenoloxidase (PPO), pectinametilesterase (PME), peroxidase (POD) e poligalacturonase (PG) da cultivar de uva Patrícia, cultivada na região de Primavera do Leste no Estado do Mato Grosso. Lavras - MG, 2004.

\begin{tabular}{lc}
\hline $\mathrm{pH}$ & 3,69 \\
$\mathrm{SS}\left({ }^{\circ}\right.$ Brix $)$ & 17,69 \\
AT (g de ácido tartárico/ & 0,8 \\
$100 \mathrm{~mL}$ de suco) & \\
PPO (U/g/minuto) & 22,15 \\
POD (U/g/minuto) & 11,59 \\
PME (U/g/minuto) & - \\
PG (U/g/minuto) & 3778,61 \\
Vitamina C (mg/mL) & 17,54 \\
\hline
\end{tabular}

A acidez titulável encontrada na cultivar Patrícia ( $0,8 \mathrm{~g}$ de ácido tartárico/100 mL de suco) foi inferior ao encontrado por Souza-Leão \& Pereira (2001) em outras variedades de uva $(0,91 \mathrm{~g}$ de ácido tartárico/100 mL de suco). Esse valor de acidez titulável possivelmente ocorre por causa das altas temperaturas na região $\left(29^{\circ} \mathrm{C}\right.$ a $\left.34^{\circ} \mathrm{C}\right)$, que coincidem com a época de maturação das bagas. Segundo Calo et al. (1996), temperaturas elevadas favorecem baixa acidez. Carvalho \& Chitarra (1984) comentam que valores acima de $1,5 \%$ considera-se acidez elevada.

As uvas em geral apresentam um valor de vitamina C de 4,6 mg/100g (REGINA, 2002). A média encontrada em nosso estudo para vitamina $C$ foi de $17,92 \mathrm{mg} / 100 \mathrm{~g}$, valor bem superior ao descrito pela literatura demonstrando que essa cultivar possui características nutricionais interessantes, pois a vitamina $\mathrm{C}$ é necessária ao homem: na síntese de vários hormônios e neurotransmissores importantes; no metabolismo do ácido fólico; na função imunitária; na função antioxidante; nas reações metabólicas de certos aminoácidos (CAMPBELL, 2003). A vitamina C pode ser facilmente oxidada, sendo a intensidade do processo dependente de fatores como luz, temperatura, presença de enzimas oxidantes ou catalisadores metálicos. A oxidação do ácido ascórbico pode ser catalisada pela enzima ácido ascórbico oxidase, pertencente ao grupo das polifenoloxidase. O primeiro passo na oxidação dessa vitamina, em frutos, envolve a formação de peróxido de hidrogênio. Mesmo em condições anaeróbicas e após a completa inativação da enzima (ácido ascórbico oxidase), a auto-oxidação do ácido ascórbico continua 
vagarosamente. Esse fenômeno pode ser explicado considerando que os vegetais contêm substâncias flavonóides que são oxidadas pelo peróxido de hidrogênio (na presença da peroxidase). A auto-oxidação do ácido ascórbico continua até que se esgote o suplemento de óxidos de flavona (FONSECA, 1974).

As amostras analisadas apresentaram uma atividade enzimática da enzima peroxidase (POD) com valor de $11,59 \mathrm{U} / \mathrm{g} / \mathrm{min} ; 22,15 \mathrm{U} / \mathrm{g} / \mathrm{min}$ para polifenoloxidase (PPO); e 3778,611 U/g/min para poligalacturonase (PG). A polifenoloxidase é encontrada praticamente em todos os tecidos vegetais, resultando na formação de pigmentos escuros, proporcionando mudanças indesejáveis nas características sensoriais dos produtos (CHITARRA \& CHITARRA, 1990). A polifenoloxidase aparentemente se torna envolvida no metabolismo quando há ruptura da célula e vacúolos com mistura dos seus conteúdos. Isso ocorre durante a senescência quando a integridade da célula é rompida, ativando a PPO latente (PIMENTA, 2001).

Nas amostras analisadas não foi detectada atividade enzimática para a enzima pectinametilesterase (PME), pois os frutos utilizados no experimento estavam maduros. Dessa forma, a PME já havia atuado desempenhando o seu papel no amadurecimento do fruto. A enzima PME é conhecida por desesterificar compostos pécticos constituintes da parede celular das plantas (FRY, 1986).

Entre as atividades enzimáticas analisadas a poligalacturonase (PG) apresentou maior valor, indicando que os frutos analisados estavam no ponto ótimo de maturação. A não determinação da enzima pectinametilesterase nos dá indício de que a atuação da enzima poligalacturonase não depende da ação da pectinametilesterase (PME), mas sim um efeito sinérgico. A hidrólise de grupos metil-éster, catalisada pela PME, produz uma pectina com menor grau de metilação, que sofre clivagem pela PG. Assim, o efeito sinergístico dessas duas enzimas tem um importante papel no processo de amolecimento do fruto, durante o estádio de amadurecimento. A desmetilação da pectina resulta em um maior número de grupos carboxílicos, o que pode facilitar a ação da poligalacturonase, que degrada substâncias pécticas, preferivelmente desesterificadas (FRY, 1986).

\section{CONSIDERAÇÕES FINAIS}

A cultivar Patrícia apresenta valor elevado de vitamina $\mathrm{C}$.

A enzima poligalacturonase (PG) apresenta maior atividade enzimática demonstrando que os frutos apresentam-se em seu estádio ótimo de maturação.
Existe efeito sinérgico entre as enzimas pectinametilesterase (PME) e poligalacturonase (PG), na cultivar Patrícia.

\section{REFERÊNCIAS BIBLIOGRÁFICAS}

ASSOCIATION OF OFICIAL ANALYTICAL CHEMISTS. Official methods of analysis of the Association of Official Analytical Chemists. 15. ed. Arlington, 1992.

BUESCHER, R. W.; FURMANSKI, R. J. Role of pectinesterase and polygalacturonase in the formation of woolliness in peaches. Journal of Food Science, Chicago, v. 43, n. 1, p. 264-266, Jan./Feb. 1978.

CALO, A.; TOMASI, D.; CRESPAN, M.; COSTACURTA, A. Relation ship between environmental factors and the dynamies of growth of te grapevine. Acta Horticulturae, Leuven, v. 427, p. 217-231, 1996.

CAMPBELL, M. K. Bioquímica. 3. ed. Porto Alegre: Artmed, 2003. 752 p.

CARVALHO, V. D.; CHITARRA, M. I. F. Aspectos quantitativos da uva. Informe Agropecuário, Belo Horizonte, v. 10, n. 117, p. 75-79, 1984.

CHITARRA, M. I. F.; CHITARRA, A. B. Pós-colheita de frutas e hortaliças: fisiologia e manuseio. Lavras: ESAL/ FAEPE, 1990. 320 p.

FONSECA, H. Bioquímica de alimentos. Piracicaba: ESALQ, 1974. 249 p.

FRY, S. C. Cross-linking of matrix polymers in the growing cell walls of angiosperms. Annual Review of Plant Physiology, Palo Alto, v. 37, p. 165-186, 1986.

GIOVANINI, E. Produção de uvas para vinho, suco e mesa. Porto Alegre: Renascença, 1999. 364 p.

GOODWIN, T. W.; MERCER, E. I. Introduction to plant biochemistry. Oxford: Pergamon, 1982. 667 p.

HULTIN, H. O.; SUN, B.; BULGER, J. Pectin methyl esterases of the banana: purification and properties. Journal of Food Science, Chicago, v. 31, n. 3, p. 320-327, May/June 1966.

KAWAMATA, S. Studies on sugar component for fruits by gas-liquid chromatography. Bulletin Tokio Agricultural Experiment Station, Tokio, n. 10, p. 53-63, 1997. 
MARKOVIC, O.; HEINRICHOVÁ, K.; LENKEY, B. Pectolytic enzymes from banana. Collection Czechoslovak Chemistry Community, London, v. 40, n. 3, p. 769-774, 1975.

PIMENTA, C. J.Época de colheita e tempo de permanência dos frutos á espera da secagem, na qualidade do café (Coffea arábica L.). 2001.145 p. Tese (Doutorado) - Universidade Federal de Lavras, Lavras, 2001.

PONTING, J. D.; JOSLYNG, M. A. Ascorbic acid oxidation and browning in apple tissue extracts. Archives of Biochemistry, [S.1.], v. 19, p. 47-63, 1948.

RATNER, A.; GOREN, R.; MONSELINE, S. P. Activity of pectin esterase and cellulase in the abcission zone of citrus leaf explants. Plant Physiology, Washington, v. 44, n. 12, p. 1717-1723, Dec. 1969.

REGINA, M. de A. Produção de mudas de videira pela enxertia de mesa. In: Viticultura e enologia: atualizando conceitos. Caldas: Epamig-ECD, 2002. p. 199-210.

RHODES, M. J. C. The maturation and ripening of fruit. In: THIMANN, K. Senescence in plants. Boca Raton: CRC, 1980. p. 157-205.

RIZZON, L. A.; GATTO, N. M. Características analíticas dos vinhos da microrregião homogênea vinicultora de
Caxias do Sul (MRH 311): análises clássicas. Bento Gonçalves: Embrapa/CNPUV, 1987. 5 p. (Comunicado técnico, 6).

SACHS, L. C. Enología. Bandeirantes: Fundação Faculdades Luiz Meneguel, 2001. 29 p.

SALUNKHE, D. K.; BOLIN, H. R.; REDDY, N. R. Storage processing and nutritional quality of fruits and vegetables: fresh fruits and vegetables. 2. ed. Boston: CRC, 1991. v. 1, $323 \mathrm{p}$.

SEYMOUR, G. B.; TAYLOR, J. E.; TUCKER, G. A. Biochemistry of fruit ripening. London: Chapman and Hall, 1993.

SOUZA-LEÃO, P. C.; PEREIRA, F. M. Avaliação de seis variedades de uvas sem sementes no submédio São Francisco. Pesquisa Agropecuária Brasileira, Brasília, v. 36, n. 4, p. 607-613, 2001.

STROHECKER, R.; HENNING, H. M. Analisis de vitaminas: metodos comprobados. Madrid: Paz Montalvo, 1967. 428 p.

VILAS-BOAS, E. V. B. Modificações pós-colheita de bananas 'Prata' (Musa acuminata x Musa balbisiana Grupo AAB) irradiada. 1995. 73 f. Dissertação (Mestrado em Ciência dos Alimentos) - Universidade Federal de Lavras, Lavras, 1995. 